\title{
Social support and its relations with positive thinking of mothers with autistic children
}

\section{Sherehan A tef Ibrahim Ibrahim (PhD)}

Assistants Professor social work with individual and families Faculty of Social Work Helwan University

\section{Eman salah Mohamed Elsayed (PhD)}

Assistants Professor social work with individual and families Faculty of Social Work Helwan University 
The Egyptian Journal of Social Work (EJSW) https://ejsw.journals.ekb.eg/e ISSN: 2356-9204 Vol 11, Issue.1, January2021 
The Egyptian Journal of Social Work (EJSW) https://ejsw.journals.ekb.eg/e

ISSN: 2356-9204

Vol 11, Issue.1, January2021

\section{Abstract:}

This study aimed at determining the relationship between social support and positive thinking for mothers with autistic children. And It also identifying indicators of the social worker roles with mothers of autistic children to achieve their social support and increase their positive thinking. the sample was chosen randomly from (72) mothers, and the study resulted proved a positive and statistically significant relationship between social support - and some dimensions of positive thinking. such as (positive expectations and optimism, and the ability to withstand suffering at a significance level 0.05 - positive risks at a significance level 0.01). The study also found that there is no relationship between social support and some dimensions of positive thinking such as (emotional control, and control of higher mental processes, desire of learning and healthy cognitive openness, and Unconditional Self-Acceptance.

\section{Key words:}

Social support - positive thinking -mothers of autistic children.

\section{Introduction:}

Autism is a very severe social disability that may lead to more general and widespread problem of learning and adaptation (Volkmar\&Wiesner, 2018, p.1). Autism is a severe developmental disorder that effects a person's ability to communicate, form relationships with others, and respond appropriately to the environment(Turkington\&Ruth,2007,p29) and it is considered a widespread disorder, which mean that it effects all aspects of child's daily life(Terrell \& Bassinger,2013,p.48). In this regard, the results of (Fleischmann,2004)study indicated that the diagnosis of autism is a difficult life experience, and it included a set of emotions such as shock, anger and guilt. According to ecological theory, the family may be exposed to many life crises situations, such as the birth of an autistic child, and these results in many problems and negative feelings for the family. The study of (Lindhom \&Michelle\&Marie,2008) indicated that parents are exposed to high levels of stress resulting from their child's autism.

An autistic child Raising is considered a bad experience, so parents are unable to go out with their friends or enjoy public activities, and some mothers may be forced to lose their jobs (Doha International Family Institute, 2018, pp.13-14). According to the concept of adaptation, the mother needs to achieve positive interaction between her and the surrounding environment in order to be able to form positive social relationships that help her to satisfy her needs and 
achieve her goals. Mother has a vital and necessary role in the education and training of the child, and the relationship between the mother and the child is more profound and clear than the father and the child, especially in the first six years of life. The mother may be exposed to low performance, stress and psychological pressure(AlQaralah\&Atakhina\&Al-Dala'in,2018, pp.4-5).In this regard, the results of (Dabrowska \&Pisula,2010) study proved that Mothers of children with autism reported higher levels of feelings of parental stress and pressure compared to mothers of children who were developing normally or suffering from other developmental disabilities.

Social support is an important source that person needs, and the presence of social support may lead to more positive perceptions in the family life cycle, as it is associated with more stable performance and more positive perceptions of the child and can improve the parentchild relationship (Gousmett,2006,p.19). The mother needs to adapt to the surrounding environmental conditions, and the lack of social support may result in many life stressors. In the study of(Boyd,2002) whose results indicated that mothers who are more vulnerable to stress are more in need of continued social support, and The level of social support is low. Also, (Siman\& Kaniel, 2011) study showed that sense of coherence, social support and quality of marriage increase the ability to cope with the stress of parenting an autistic child. According to the characteristics of the ecological theory, families of autistic children are able to bring about the necessary changes to accommodate the child's disability, provided that the families are enabled to obtain appropriate opportunities for social support.

A positive family environment is characterized by high levels of positive emotional expression and low levels of conflict. Families need to cooperate in all activities (DIFI, 2018, p35). Since a person is a positive thinker by nature, if a positive environment is available to him, we will find that he behaves positively (Biles \& Seligman,2009, p.13). (Yunus, 2018) study found that there is a positive and significant correlation between positive thinking skills and posttraumatic development. Cognitive theory holds that there is an interaction between what an individual thinks, feels and how he behaves. These thoughts affect social performance and his psychological health. Thinking is a cognitive phenomenon that may contain an unorganized thought that needs to be controlled (Minda, 2015, p.2). Parents may feel very anxious as a result of their overthinking about what might happen when their children are adults, 
or fear that their children with autism will not receive care if the parents are unable to provide them with the necessary care (DIFI, 2018, p.13) In this direction, the results of (Daine \& Naomi \& Thomas, 2011)study were shown, Marital compatibility mediates positive perceptions and the well-being of the mother, and mothers who had positive perceptions, ideas and expectations for the child had a higher marital compatibility, and marital compatibility reduces negative perceptions on the mother. Cognitive theory states that the acquisition and application of knowledge about the nature of human thinking increases positive thinking processes. As well as the results of Ekas \&Tidman \& Timmons, (2019)study where it was found that mothers with high levels of spirituality had positive thinking and vision so that they consider the presence of an autistic child as an increase or extension of a positive contribution to the family. The results of Cappe \&Marion\& Adrien (2011) study showed that parents felt more guilt and reported beliefs that are more false, they need to focus on handling stress and emotions, modifying false beliefs and solving the daily problems. The results of Al-Qarala\& Atakhaina \& Al-Dla'in, (2018) study also indicated that the presence of an autistic child increases the burden of the family, especially the mother, causing her stress and anxiety and affecting her social skills, which causes low self-esteem, unacceptability and inability to Selfmanagement. According to the concept of self-esteem, the mother needs to feel the respect of others for her and their encouragement for her because of its positive effects on her thinking and behavior and improving her social relationship with the surrounding systems.

Positive thinking drives positive forces that come with positive results, if a person wants to change his circumstances, he must first change his or her thinking (Bill, 2001, p. 200). The results of the study of Saud \&Bataina (2011) pointed out that the training program helped in modifying their awareness of the autism concept, which contributed to modify their cognitive component and their feelings towards their children. As the study showed the need of parents to modify their cognitive and increase their information and knowledge, which contributed to increase their acceptance to their children and increasing their experiences. Study of Al Deeb, (2016) showed that there is a set of needs for mothers, the first of which is community needs represented in community support, then the cognitive and training needs represented by their need for learning and cognitive openness, and then social and material needs. The study of Bragel, (2017)indicated that mothers of autistic children prevail among them 
The Egyptian Journal of Social Work (EJSW) https://ejsw.journals.ekb.eg/e ISSN: 2356-9204

Vol 11, Issue.1, January2021

internal control, and this shows the mother's belief about her ability to control things around her and her belief in the possibilities that qualify her to accept her child and help him to develop his skills, and mothers with high internal control have the ability to face the stressors. The study of Zoghdi, (2018) which referred to the nature of perceptions of mothers, which focused on the ability to endure pain and suffering. And that a high level of stress can cause harmful automatic thoughts. Many life problems result from cognitive distortions in reality that may lead to unrealistic interpretations of surrounding events or circumstances. Also ecological theory can be used by social worker to analyze and understand the complex network of relationships and that influence the client world. The main aim of social work is to strengthen the adaptive capacities of people and to influence their environments ,so that transactions are more adaptive. Through the previous presentation, the study problem identified in a question:

What is the relation between social support and positive thinking of mothers with autistic children?

\section{Theoretical Guidelines of Research:}

\section{Ecological theory:}

Ecological theory highlights the significance of social environment as a key framework for human behavior (Aila\&Kati, 2018, p.204). It focuses on the person in the environment, interactions and ongoing transactions between people, families, groups and/or communities, and it's focuses on the dynamics of interaction between a person and his social and physical environment (Deacon \&Macdonald, 2017, p.89). Also it Seeks to support individuals in creating a person: an appropriate environment that promotes diverse and supportive environments, positive human growth and development. It sees individuals able to deal with their environments and are able to make the necessary changes in it or themselves, provided that their energy and potential are released, and remove the obstacles that prevent the individual from satisfying his needs, and enable the individual to achieve their legitimate desires and goals (Teater, 2014, p.28).

\section{Cognitive theory:}

Cognitive theory is based on the concept that there is a correlation between what one thinks and what one feels, and how one behaves, one's thoughts determine his or her feelings and then determine his or her behavior (Cooper \&Lesser,2008,p.140).Cognitive theory includes ideas, knowledge, beliefs, assumptions, expectations, trends and perceptions, our ideas can reflect what is happening in the outside world and even may be distorted to the point that we can 
The Egyptian Journal of Social Work (EJSW) https://ejsw.journals.ekb.eg/e

ISSN: 2356-9204

Vol 11, Issue.1, January2021

misunderstand what is happening around us, most of the problems of life are the result of cognitive misunderstandings or beliefs that are not supported by external evidence(Walsh,2006,p.108).

\section{The objectives of the study:}

1. Determining the nature of relationship between social support and positive thinking of mothers with autistic children.

2. Identify indicators of social worker role with mothers of autistic children to achieve social support and increase positive thinking for them.

\section{Study concepts}

\section{Social support concept:}

It defined as a network of individuals who are able to provide information, resources, emotional and psychological support both through official institutions and through informal institutions (Gousmett, 2006, pp.18-19).Also defined as a group of relationships between a group of people that provide assistance in situations through the social support network as family, friends, neighbors, coworkers, volunteers and specialists (Davies, 2000, p. 329).

The definition of social support is determined theoretically as an assistance and participation by information, emotional, behavioral and physical received by the mother of the autistic child through others in the social environment as relatives, friends and neighbors.

The definition of social support is determined procedurally by the degree to which the mother with autistic child gets on the scale of social support through the following dimensions :( information support- emotional integration - emotional support - behavioral support - material support).

\section{Positive thinking concept:}

Neck \&Manz (1992) defined it as having a number of positive, optimistic expectations about the future and being convinced of its ability to succeed (p682). It is also means an individual having a set of convictions and beliefs helps him making positive expectations (Scheier \& Carver, 1993, p.26)

Definition of positive thinking theoretically as a type of thinking acquired by the mother through a set of skills that helps her to overcome stressful situations and to achieve successes in her life.

Definition of positive thinking procedurally by The degree to which mothers with autistic children are singled out on the positive thinking scale, which includes the following dimensions(positive expectations, optimism, emotional control, and control of higher mental processes, 
The Egyptian Journal of Social Work (EJSW) https://ejsw.journals.ekb.eg/e

ISSN: 2356-9204

Vol 11, Issue.1, January2021

unconditional self-acceptance, desire of learning and healthy cognitive openness, positive risks, ability to withstand the suffering).

\section{Methodology:}

This study belongs to the pattern of descriptive and analytical studies that determine the relationship between two variables, social support and positive thinking for mothers of autistic children This study relied on the method of the social survey sample.

\section{Study hypothesis:}

There is a positive statistically significant relationship between social support and positive thinking for mothers of autistic children.

\section{The sub- hypothesis are the following:}

1 -There is a positive statistically significant relationship between social support، positive expectations and optimism for mothers with autistic children.

2 -There is a positive statistically significant relationship between social support، emotional control، and control of higher mental processes for mothers of autistic children.

3 -There is a positive statistically significant relationship between social support، desiring of learning and healthy cognitive openness ,for mothers with autistic children.

4 -There is a positive statistically significant relationship between social support and the unconditional self-acceptance of mothers with autistic children.

5-There is a positive statistically significant relationship between social support and the positive risks for mothers with autistic children.

6 -There is a positive statistically significant relationship between social support and the ability to withstand the suffering of mothers of autistic children.

Sample: The study sample: - The study sample consisted of 72 mothers of autistic children, representing $40 \%$ of the mothers who were selected by the intentional sample method according to the following conditions:

1- Their children are between 3-9 years old, as autism disability cannot be diagnosed before the child reaches three years of age, and the beginning of the diagnosis of disability is a shock to the entire family, especially the mother, which makes her in need of social support from those around.

2- The mother's education level should be at least medial so that she can deals with her autistic child in a positive way. 
The Egyptian Journal of Social Work (EJSW) https://ejsw.journals.ekb.eg/e

ISSN: 2356-9204

Vol 11, Issue.1, January2021

3-the autistic child lives with his normal family (father mother ,brother, sister).

4-the study should apply by electronic way on mothers with autistic children who accept to co-operate with the researches.

\section{Third: - Tools :}

A- The Scale of Social Support for Mothers of Autistic.

B- Positive thinking scale .

The first scale: A measure of social support for mothers of autistic children. The researcher adopted the scale of social support for mothers of autistic children (Prepared / Desouki, 2007 )

Scale description: The scale consists of 5 main dimensions, 48 phrases distributed over these dimensions (informational support, Social integration, Emotional support, Behavioral support, Financial support) all dimensions consiste of 10 statement expect the financial support dimension consists of 8 statement.

The researchers re-conducted the validity of the scale to verify the reliability of the research.

The researchers re-conducted validation and reliability of the scale to verify its suitability for the current research. Validity and Reliability were verified as follows:

\section{A- Validity of the scale: -}

\section{Internal consistency validity :-}

The researchers verified the validity of the social support scale, where the researchers used internal consistency, as this type of honesty was calculated by applying the scale once on a sample consisting of (10) mothers with autistic children, it shows that the correlation coefficient are high and function at the level of significance $(0.01),(0.05)$, which indicates the validity of the scale to an appropriate degree where the results can be relied upon.

\section{B - Measurement of scale reliability:}

- Split - half (Spearman - Brown).

And by using the Spearman - Brown equation for the split half, where the correlation coefficient was calculated between the scores of the individual responds and the scores of the marital expressions for a sample of 10 mothers, and the results of the test came as follows: 


\begin{tabular}{||cr|}
\hline The Egyptian Journal of Social Work (EJSW) https://ejsw.journals.ekb.eg/e \\
ISSN: 2356-9204 & Vol 11, Issue.1, January2021 \\
\hline
\end{tabular}

Table No. (2)It shows the reliability coefficients of the scale by the half-segmentation method

\begin{tabular}{|l|l|}
\hline The dimensions & Spearman Brown \\
\hline informational support & 0.94 \\
\hline Social integration & 0.96 \\
\hline Emotional support & 0.89 \\
\hline Behavioral support & 0.86 \\
\hline Financial support & 0.93 \\
\hline Scale as a whole & 0.92 \\
\hline
\end{tabular}

Table No. (2) shows the existence of a high degree of stability in all dimensions of the scale, so that the results of the instrument can be relied upon, indicating that the scale has an appropriate degree of stability.

\section{Correction of scale : -}

The scale contains three responses: agree 3 degrees, agree to a certain extent two degrees, disagree, one degree in the case of positive expressions, i.e. those belonging to social support, while agreeing takes one degree, agree to some degree two degrees, and disagree three degrees in the case of statements Negativity that expresses a lack of social support.

Table No. (3) The key to correcting the social support scale

\begin{tabular}{|c|c|c|c|c|c|c|c|c|}
\hline 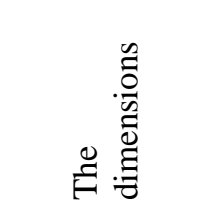 & 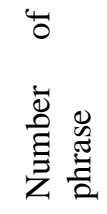 & $\begin{array}{l}\frac{0}{3} \\
\frac{\pi}{3} \\
\overline{0} \\
0 \\
0 \\
0 \\
0\end{array}$ & $\begin{array}{l}\overrightarrow{0} \\
\frac{0}{000} \\
.1\end{array}$ & 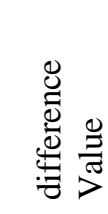 & 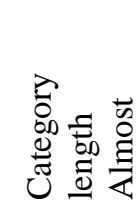 & $\begin{array}{l}0 \\
0 \\
0 \\
3 \\
0 \\
0 \\
0\end{array}$ & 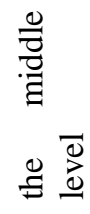 & 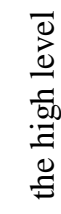 \\
\hline $\begin{array}{l}\text { informational } \\
\text { support }\end{array}$ & 10 & 10 & 30 & 20 & 7 & $\begin{array}{l}-10 \\
17\end{array}$ & $24-17$ & $\begin{array}{l}-24 \\
30\end{array}$ \\
\hline $\begin{array}{l}\text { Social } \\
\text { integration }\end{array}$ & 10 & 10 & 30 & 20 & 7 & $\begin{array}{l}-10 \\
17\end{array}$ & $24-17$ & $\begin{array}{l}-24 \\
30\end{array}$ \\
\hline $\begin{array}{l}\text { Emotional } \\
\text { support }\end{array}$ & 10 & 10 & 30 & 20 & 7 & $\begin{array}{l}-10 \\
17\end{array}$ & $24-17$ & $\begin{array}{l}-24 \\
30\end{array}$ \\
\hline $\begin{array}{l}\text { Behavioral } \\
\text { support }\end{array}$ & 10 & 10 & 30 & 20 & 7 & $\begin{array}{l}-10 \\
17\end{array}$ & $24-17$ & $\begin{array}{l}-24 \\
30\end{array}$ \\
\hline $\begin{array}{l}\text { Financial } \\
\text { support }\end{array}$ & 8 & 8 & 24 & 16 & 5 & $\begin{array}{c}-8 \\
13 \\
\end{array}$ & $18-13$ & $\begin{array}{l}-18 \\
23 \\
\end{array}$ \\
\hline $\begin{array}{l}\text { Scale as a } \\
\text { whole }\end{array}$ & 48 & 48 & 144 & 56 & 19 & $\begin{array}{l}-48 \\
67\end{array}$ & $86-67$ & $\begin{array}{l}-86 \\
105 \\
\end{array}$ \\
\hline
\end{tabular}

The second scale: - Positive thinking for mothers of autistic children

The researchers adopted the positive thinking scale for mothers of autistic children (Prepared / Melhem, 2013). 
The Egyptian Journal of Social Work (EJSW) https://ejsw.journals.ekb.eg/e

ISSN: 2356-9204

Vol 11, Issue.1, January2021

Scale description: the scale consists of 6 main dimensions, 48 statement distributed over these dimensions, as after positive expectations and optimism it consists of 7 statement, and after emotional control and control of higher mental processes it consists of 8 statement, and after the desiring of learning and healthy cognitive development consists of 10 statement, and the dimension of selfacceptance Unconditional also contains 10 phrases, as is accumulated after the positive risks 6 .

statement, while the ability to withstand suffering consists of 7 statement

The researchers re-conducted validation and reliability of the scale to verify its suitability for the current research. Validity and Reliability were verified as follows:

\section{B- Validity of the scale: -}

\section{-Internal consistency validity :-}

The researchers verified the validity of the positive thinking scale, as the researcher used the validity of internal consistency, as this type of validity was calculated by applying the scale once on a sample of (10) mothers of autistic children, and it shows that the values of the resulting correlation coefficient are high and function at the level of significance $(0.01),(0.05)$, which indicates the validity of the scale to an appropriate degree where the results can be relied upon.

\section{$B$ - reliability of scale:}

The researcher calculated the reliability of the scale by using the following parameters:Split - half (Spearman - Brown) where the correlation coefficient was calculated between the scores of the individual expressions and the scores of the marital expressions for a sample of 10 mothers, and the results of the test came as follows:

Table No. (5) It shows the stability coefficients of the scale by Split - half method

$(\mathbf{N}=\mathbf{1 0})$

\begin{tabular}{|l|l|}
\hline The dimensions & Spearman Brown \\
\hline Positive expectations and optimism & $* * 0.86$ \\
\hline Emotional control and control of higher mental processes & $* * 0.78$ \\
\hline desire of learning and healthy cognitive openness, & $* * 0.89$ \\
\hline Unconditional self-acceptance & $* * 0.91$ \\
\hline Positive risks & $* * 0.88$ \\
\hline ability to withstand the suffering & $* * 0.85$ \\
\hline Scale as a whole & $* * 0.86$ \\
\hline
\end{tabular}

Table No. (5) shows the existence of a high degree of stability in all dimensions of the scale so that the researcher can rely on the findings of the instrument, which indicates that the scale has an appropriate degree of stability. 


\begin{tabular}{||cr|}
\hline The Egyptian Journal of Social Work (EJSW) https://ejsw.journals.ekb.eg/e \\
ISSN: $2356-9204$ & Vol 11, Issue.1, January2021 \\
\hline
\end{tabular}

\section{Scale correction key:: -}

The scale consists of two phrases (a) and (b) where (a) refers to positivity in thinking, and (b) refers to negativity in thinking, and both of them describe some thinking styles and a way the mother has to confront social situations and her interpretations to them, and the mother gets two degrees when she chooses The positive statement (a), and the mother gets one score when she chooses the negative statement (b). Thus, the degrees of the scale range from (48) degrees, which is the lowest degree of positive thinking to (96) degrees, which is the highest degree of positive thinking of the mother on the scale.

\section{Results :}

The main hypothesis of the study: - There is a positive statistically significant relationship between social support and positive thinking for mothers of autistic children.

Table No. (6) Explains the relationship between social support and positive thinking for mothers of autistic children $\quad \mathbf{N}=72$

\begin{tabular}{|l|l|l|l|l|}
\hline Dimension & Mean & S.D & correlation & $\begin{array}{l}\text { Level of } \\
\text { significance }\end{array}$ \\
\hline Social support & 94.95 & 34.21 & $* 0.262$ & 0.05 \\
\hline Positive thinking & 86.14 & 7.02 & \multirow{2}{*}{$* 0.05$} \\
\hline
\end{tabular}

The following table shows That there is a positive relationship with statistical significance between social support and positive thinking for mothers of autistic children at a significance level of 0.05 , and therefore the main hypothesis of the study is accepted.

Table No.(7) Explains the relationship between social support and the positive thinking dimensionsofmothersofautisticchildren $\mathrm{N}=72$

\begin{tabular}{|c|c|c|c|c|}
\hline Dimensions & Mean & S.D & correlation & $\begin{array}{l}\text { Level of } \\
\text { significance }\end{array}$ \\
\hline Social support & 94.65 & 34.21 & \multirow{2}{*}{$* 0.270$} & \multirow{2}{*}{0.05} \\
\hline Positive expectations and optimism & 12.21 & 1.44 & & \\
\hline Social support & 94.65 & 34.21 & \multirow[b]{2}{*}{0.054} & \multirow[b]{2}{*}{ Non-Significant } \\
\hline $\begin{array}{l}\text { Emotional control and control of } \\
\text { higher mental processes }\end{array}$ & 13.76 & 1.85 & & \\
\hline Social support & 94.65 & 34.21 & \multirow[b]{2}{*}{0.176} & \multirow[b]{2}{*}{ Non-Significant } \\
\hline $\begin{array}{l}\text { desiring of learning and healthy } \\
\text { cognitive openness, }\end{array}$ & 18.82 & 1.43 & & \\
\hline Social support & 94.65 & 34.21 & \multirow{2}{*}{0.026} & \multirow{2}{*}{ Non-Significant } \\
\hline Unconditional self-acceptance & 17.58 & 1.86 & & \\
\hline Social support & 94.65 & 34.21 & \multirow{2}{*}{$* * 0.472$} & \multirow{2}{*}{0.01} \\
\hline Positive risks & 10.29 & 1.58 & & \\
\hline Social support & 94.65 & 34.21 & \multirow{2}{*}{$* 0.253$} & \multirow{2}{*}{0.05} \\
\hline ability to withstand the suffering & 13.47 & 1.19 & & \\
\hline
\end{tabular}

The table above shows :That there is a positive relationship with statistical significance between social support, positive expectations 
and optimism for mothers of autistic children at a level of 0.05 morale, and therefore the first hypothesis of the study is accepted, and there is no positive statistically significant relationship between social support and emotional control and control of higher mental processes of mothers of autistic children Therefore, it is rejected, as well as there is no positive statistically significant relationship between social support, love of learning and healthy cognitive openness, for mothers of autistic children, and thus the third hypothesis of the study is rejected, and also there is no positive statistically significant relationship between social support and unconditional self-acceptance of mothers of autistic children. Therefore, the fourth hypothesis of the study is rejected, but there is a positive relationship with statistical significance between social support and positive risks for mothers of autistic children at a significance level of 0.01 , and therefore the fifth hypothesis of the study is accepted, and there is a positive relationship with statistical significance between social support and the ability to withstand suffering. For mothers of autistic children, at the level0,05.

\section{Discussion the results of the study}

The current study found a positive statistically significant relationship between social support and positive thinking of mothers with autistic children at a level of (0.05). The results of the current study are consistent with the results of some previous studies such as the results of (Boyd, 2002) study, and (Desouki, (2007) study which indicated that the use of the environmental input led to increased social support for mothers. Also Siman \& Kaniel,(2011) study showed that sense of coherence and social support increasing the ability to cope with the stress, Support plays an important role in alleviating painful and stressful events, which indicates that mothers with autistic children are in need of social support, and since the human is a positive thinker by nature if he has a positive environment we will find him acting positive, but if the environment in which he grows is negative, it will affect the way he thinks (Biles\&Seligman,2009,p.13). According to the concept of adaptation, the mother needs to achieve positive interaction between her and the surrounding environment in order to be able to form positive social relationships that help her to satisfy her needs and achieve her goals, and the cognitive theory confirmed that there is a mutual interaction between what one thinks and what one feels, and how it behaves, the individual's thoughts determine his feelings and then determine his behavior. The mother's positive thinking will reflect on her actions and then her life. 
The study found a positive relationship statistically between social support and positive expectations and optimism. This is consistent with Daine \&Naomi \&Thomas, (2011) study that showed that mothers who have positive perceptions had marriage adjustment. This was in keeping with the results of Ekas \&Tidman \&Timmons, (2019) study where it found that mothers with high levels of spirituality had positive thinking. According to cognitive theory beliefs, expectations, and perceptions can reflect what is happening in outside world, and the researchers believe that if mothers receive social support represented in the informal support as relatives, friends and neighbors it may increase their positive expectations. According to ecological theory, the niche accorded to mother affects her performance of various roles.

The study found that there is no statistically functioning relationship between social support and emotional control and control of the higher mental processes of the mothers, and this is consistent with the results of Brajel, (2017) study that found that the mother sees herself responsible for this child. This is supported by the positive thinking, and belief that a person is capable of enduring and overcoming all difficulties. The study found that there is no statistically functioning relationship between social support and desire of learning and healthy cognitive openness for mothers, and this is consistent with the results of Al Deeb,(2016) study which indicated that one of the most important needs for mothers are the cognitive and training needs, According to cognitive theory, thinking and problem solving are not only the result of the mother's interaction with environmental events, but also with her understanding of these events. The study also found that there is no statistically significant relationship between social support and unconditional self-acceptance of mothers. This is consistent with the results of the study of AlQaralah \& Atakhina\& Al-Dala'in,(2018) that the presence of an autistic child that causes a lack of self-esteem, and disagrees with the results of Al-Aqari,(2018) study which indicated that the lack of family support and the lack of other acceptance the child made them a negative perception of themselves. According to the ecological theory, increased stressors pose a danger to the mother and threaten her social and psychological being and the negative effects of the inability to adapt and the inability to exercise the tasks of daily life and decrease motivation, which affect her self-acceptance. According to cognitive theory beliefs, expectations, and perceptions can reflect what is happening in outside world, and the researchers believe that if mothers 
with autistic children receive social support represented in the informal support as relatives, friends and neighbors it may increase their positive expectations. The niche accorded to mother affects her performance of various roles. In addition, that a high level of stressors can cause harmful automatic thoughts. Negative beliefs and distorted thoughts need to be modified to fit in her the environment.

The study found a statistically functional relationship between social support and positive risks for mothers. This is in line with the results of Brajel (2017) study, which indicated that mothers have the ability to cope with the stressors through positive risks. This is in line with the results of Zoghdi (2018)study, and this shows the need of the mother for social support to obtain stability and family cohesion.

From the above the researchers believe that the existence of autistic child will undoubtedly affect the relationships and interactions of the mother, which may lead to increase the different stressors which she is exposed, but if the necessary social support is available for her, this will have a positive impact on some of her positive thinking skills as the current study showed, and it requires cognitive reconstruction of mothers.

\section{Indicators of the roles of social worker with mothers of autistic children to achieve social support and increase positive thinking:}

1--The role of the teacher

In order to achieve the information support, the social worker plays the role of the teacher by conducting educational seminars for mothers to provide them with information on how to deal with their children.

2- The role of the broker - mediator

The social worker helps mothers access the institutions in the local community that provide services to them

3 - The role of the advocator : to advocate the rights of mothers to obtain the required services in an appropriate manner in the concerned institutions

4- The role of the caregiver: The social worker helps mothers to know the material assistance provided by institutions for them, to provide mothers with some life skills that help them deal with the problems of their autistic child.

5 -The role of the programmer developer: through designing workshops and counseling programs for mothers to provide them with modern methods that help them think positively, train mothers on effective strategies that help them increase the positive outlook and create optimism in them. 


\section{The Egyptian Journal of Social Work (EJSW) https://ejsw.journals.ekb.eg/e}

ISSN: 2356-9204

Vol 11, Issue.1, January2021

6- The role of the enabler : by helping mothers to express themselves using the emotionally emptying method and helping them to identify the strengths inherent in themselves, their capabilities and resources to satisfy their needs and achieve their goals.

7- The role of the therapist : by discussing some abnormal methods in facing stresses so that they can face situations without referring to the institution, Amending misconceptions in mothers and modifying negative self-talk in order to reduce negative stresses and emotions, which helps in modifying their behaviors and giving them a new network of relationships, which helps them to reconcile with themselves and with others and increase their self-esteem as well.

\section{Proposed research:}

-The effectiveness of a mentoring program to develop positive thinking skills with mothers of autistic children

-Social support and its relationship to the maladaptive behavior of autistic children is mothers.

\section{Search limits:}

- Delayed approval by officials to implement the practical side, and sometimes their refusal to conduct research.

-Weak interest of some mothers for the benefit of research as a kind of community culture

\section{Refrances:}

Ibrahim,A. (2008) Eye of the Mind, "A Psychotherapist's Guide to Positive Cognitive Therapy, Cairo, Dar Al-Kitab.

Al- Aqari, D. (2018) Self-esteem and the power of the ego in mothers of autistic children, Master's Thesis, Belhadj Bouchaib University Center, Ain Tamoshant, Institute of Literature and Languages, Department of Social Sciences.

Al-Deeb,A.A. (2016). Psychological stress and the needs of mothers of children with autism spectrum disorder and the relationship between them in the United Arab Emirates, Master Thesis, United Arab Emirates University, College of Education, Department of Special Education.

Al-Qaralah\&Atakhina\&Al-Dala'in. (2018). The effectiveness of a family counseling program in developing self-management and self-esteem among mothers of autistic children in Karak Governorate, An-Najah University Research Journal (Human Sciences), Volume 32 (1), pp. 1-30.

Biles \& Seligman .(2009). translated by Hend Rushdie, The Power of Positive Thinking, Cairo, Kunooz Publishing and Distribution.

Bill,N.F. (2001). The Power of Positive Thinking, Cairo, Seabars Press, 7th Edition, Translated by Youssef Eskandar.

Boyd, B.,( 2002). Examining the relationship between stress and lack of social support in mothers of children with autism, focus on Autism and other Developmental Disabilities, vol (17) No, (4)

Brajel,E. (2017). The relationship of the control source to psychosomal disorders in mothers of autistic children, Ph.D., Mohamed Khidir University, Biskra, College of Humanities and Social Sciences, Department of Social Sciences. 


\section{The Egyptian Journal of Social Work (EJSW) https://ejsw.journals.ekb.eg/e}

ISSN: 2356-9204

Vol 11, Issue.1, January2021

Cooper.G,M \& Lesser.G,J. (2008). Clinical Social work practice An Integrated Approach, USA, Perason,3ed .

Dabrowska,A.,\&Pisula,E.(2010).Parenting stress and coping styles in mothers and fathers of pre-school children with autism and down syndrome, Journal of Intellectual Disability Research, 54(3), 266-280

Daine\&Naomi\&Thomas.(2011).Feeling good, feeling bad: Influences of maternal perceptions of the child and marital adjustment on well-being in mothers of children with an autism spectrum disorder, Journal of Autism and Developmental Disorders. Vol.41(7), Jul 2011, pp. 848-858

Davies,M.(2000).The Black Well Encyclopaedia Of Social Work,New York,Black Well Publishers Itd.

Desouki,M.( 2007). The relationship between the use of the environmental perspective in the service of the individual and the increase in social support for mothers of autistic children, published research, 20th scientific conference, Social Work, Helwan University.

Doha International Family Institute DIFI. (2018): Well-being of families living with autism spectrum disorder in Qatar,Doha, University House Hamd Ebn-Khalifa Publishing

Yunus,E.Y. (2018). Positive thinking skills and their relationship to post-traumatic development among mothers of children with autism spectrum disorder, Journal of Scientific Research in Education, Ain Shams University, Sciences and Education, Vol 19(5).

Ekas,N.\&Tidman,L.\&Timmons,L.(2019).Religiosity/Spirituality and Mental Health Outcomes in Mothers of Children With Spectrum Disorders The Mediating Role Positive Thinking,Journal of Autism and Devolopmental Disorders ,vol(49),11,pp. 4547-4558

Fleischmann. A.( 2004) .Narratives published on the Internet by parents of children with autism: What do they reveal and why is it important?Focus on Autism and Other Developmental Disabilities, Vol(19) No(1).

Gousmett,S,L .(2006).Families of children with developmental Disabilities : Family environment, social support and sibling well-being, Mas dissertation, university of Canterbury

Lindhom \&Michelle\& Marie. ( 2008). Stress, copying and quality of life in families raising children with autism, United States, California : Allian International University.

Melhem,N.N. (2014). The effectiveness of a training program based on developing some positive thinking skills in reducing psychological pressures among mothers of autistic children, Ph.D., Damascus University, College of Education, Department of Special Education

Minda,J.P.(2015).The Psychology of Thinking ,SAGE Puplication

Neck,C.P. \& Manz,C.C.(1992). Though self-leadership the influence of self-talk and mental imagery on performance, Journal of Organizational Behavior ,13,pp.681-699.

Saud,M \&Al-Bataina,A.( 2011). The Impact of a Training Program in Modifying the Attitudes of Parents of Autistic Children towards their Children, Educational Sciences Studies, Vol38( 2), pp. 504-524

Terrell.K\& Basinger.W.T. (2013). Autism and hyperactivity, impaired reading and functioning, Riyadh, King Fahd National Library, translated by Abboud. M. 


\begin{tabular}{||cr||}
\hline The Egyptian Journal of Social Work (EJSW) https://ejsw.journals.ekb.eg/e \\
ISSN: $2356-9204$ & Vol 11, Issue.1, January2021 \\
\hline \hline
\end{tabular}

Turkington.C \&Ruth. A. (2007). The Encyclopedia of Autism Spectrum Disorders ,united states of America, NewYourk ,An Imprint of Infobase Publishing.

Walsh,J.(2006). Theories for direct Social work practice,USA, Brooks.

World Innovation Summit for Health(WISH)(2016). Autism is a global framework for action, WISH Autism Forum Report

Zoghdi,N.( 2018). Social Perceptions of Mothers of Autistic Children, Master Thesis, Al-Wadi University, College of Humanities and Social Sciences.

Scheier, M. F. \& Carver, C. S. (1993). On the Power of Positive Thinking: the Benefits of Being Optimistic. Current Direction in Psychological Science, Feb 2, (1), $26-30$.

Siman,A\& Kaniel,S.(2011). Stress and personal resource as predictors of the adjustment of parents to autistic children: A multivariate model, Journal of Autism and Developmental Disorders. Vol.41(7), Jul 2011, pp. 879-890.

Cappe,E.W \&Marion,B.R\& Adrien,J.L.(2011). Quality of life: A key variable to consider in the evaluation of adjustment in parents of children with autism spectrum disorders and in the development of relevant support and assistance programmes, An International Journal of Quality of Life Aspects of Treatment, Care \& Rehabilitation, Vol.20(8), Oct 2011, pp. 1279-1294

Volkmar,F.R\&Wiesner,L.A. (2018). Essential Clinic Guide to Understanding and Treating Autism, United States, New Jersy:Wiley.

Aila,L.M\&Kati,N.(2018). Ecological Theories, In Social Work Theory and Method,Ed by Thompson\&Stepney,N Y ,Taylor\&Francis.

Deacon,L\&Macdonald,J.S.(2017). Social Work Theory\&Practice, UK, SAGE.

Teater, B. (2014). An introduction to applying social work theories and methods, NY, Mc Graw Hill Education,2ed. 